\title{
Ultrastructural investigations of enzyme treated cell wall material from industrial by-products
}

\author{
F. M. ENGELS ${ }^{1} \&$ N. A. SCHALK \\ Department of Plant Cytology and Morphology, Wageningen Agricultural University, \\ Wageningen, Netherlands \\ ${ }^{1}$ Present address: Department of Field Crops and Grassland Science, Wageningen Agri- \\ cultural University, Haarweg 333, NL 6709 RZ Wageningen, Netherlands
}

Received 24 October 1991; accepted 21 February 1992

\begin{abstract}
Ultrastructural investigations of glycanase treatments of cell wall material from industrial by-products was carried out with the enzyme-thiocarbohydrazide-silver protein technique (ETAg). Driselase, gamanase and an experimental enzyme preparation were used. Carbohydrate hydrolysis was found in cell walls and cell contents in 1-2 cell layers at the surface of $0.2 \mathrm{~mm}$ plant particles. Enzyme activity was detected to some extend inside unlignified and lignified cell walls. The absence of any reaction in some sublayers of the cell wall was indicative for, either the absence of polysaccharide substrate or a very tied interaction of cell wall components preventing enzymic activity or the absence of typical enzymes in crude preparations. The ETAg-technique can be usefull to provide information about structural limitations of poorly degradable plant materials.
\end{abstract}

Keywords : cell wall, degradation, enzyme treatment, silver staining, ultrastructure

\section{Introduction}

Industrial by-products e.g. palm kernel meal and sunflower meal are used as additional feed components in animal husbandry. These products contain polysaccharides which could serve as an energy source for monogastrics. However, their digestive system is unable to reach maximal benefit from the products by lack of appropriate enzyme activities. Enzymic pretreatment of cell wall material can be applied to loosen or decompose macromolecular interactions before animal degradation (Graham et al., 1986; Malek et al., 1988), or to gain fundamental knowledge on enzyme and polysaccharide interaction or on localization and carbohydrate composition of cell walls.

In preceeding experiments specific macromolecular compounds were localised in cells and cell walls of tissues from palm kernel and sunflower meal in relation to chemical extractions of carbohydrates (Düsterhöft et al., 1991). The study provided information on types of polysaccharides which could be investigated further during degradation by enzymic treatments of cell wall material. 
Recently, enzyme-thiocarbohydrazide-silver protein (ETAg) treatment of cell walls has been introduced which enables structural localization of cell wall polysaccharides and site of activity of hydrolytic enzymes (Joseleau \& Ruel, 1985). In the present study this method was used to investigate the interaction of enzymes and carbohydrates of cell wall material in industrial by-products.

\section{Materials and methods}

Sunflower (Helianthus annuus) meal and palm kernel (Elaeis guineensis) meal were provided by Hendrix Nutrition Nederland BV (Boxmeer, the Netherlands). Sunflower meal contains lignified pericarp (hull) and seed fractions (embryo, testa and endosperm) and palmpit meal contains lignified endocarp (shell) and thick walled endosperm (with a small embryo). The meals were treated with hexane and with protease to remove residual fat and protein, respectively (Düsterhöft et al., 1991).

Driselase (Sigma) and an experimental preparation (A) with broad spectra of hemicellulase, cellulase and pectolytic activities, and gamanase (Novo), with mannanase as main activity, were used in concentrations of $100 \mathrm{mg}$ protein/litre of a $0.05 \mathrm{M}$ Na-acetate buffer at $\mathrm{pH}$ 5.0. Cell wall material was milled to a fine powder $(<0.2 \mathrm{~mm})$ using a freezer-mill (Spex Ind. Inc. Edison, USA). Enzyme incubations were carried out with $20 \mathrm{mg}$ non-starch polysaccharide per $1 \mathrm{ml}$ buffer during $72 \mathrm{~h}$ at $40^{\circ} \mathrm{C}$.

Enzyme-thiocarbohydrazide-Ag protein staining (ETAg) was modified after Joseleau \& Ruel (1985) and carried out on plant particles in subsequent steps.

(E): incubation of cell wall material with enzymes was at $40^{\circ} \mathrm{C}$ during $72 \mathrm{~h}$ after which the material was washed thoroughly in distilled water.

(T): Two g thiocarbohydrazide was dissolved in 3.5 molar glacial acetic acid. Enzyme treated particles were left for $24 \mathrm{~h}$ in this solution and then washed, $3 \times$, during $15 \mathrm{~min}$ in $3.5,1.75$ molar glacial acitic acid and finally in aqua dest. respectively.

(Ag): $10 \mathrm{~g}$ silver-protein (Merck) in 1 litre aqua-dest. was used to treat plant particles in darkness for $30 \mathrm{~min}$. Subsequently they were washed thoroughly with distilled water, dehydrated and embedded in Epon 812. This procedure is further refered as 'en-block method'.

\section{Control of ETAg staining in plant particles}

TAg solely: omiting the enzyme incubation, the staining was applied on plant particles to localize in situ reducing end-groups.

Dimedon blocking-TAg: reducing end-groups were blocked with $10 \mathrm{~g}$ dimedon (5,5 dimethylcyclohexaan-1,3-dinon; Merck) in 0.175 molar glacial acetic acid following TAg treatment.

Denaturated enzyme-TAg: Enzyme preparations were denaturated during 15 min at $100{ }^{\circ} \mathrm{C}$ and followed by TAg.

Combined enzyme-TAg (ETAg): treatment with dimedon, enzyme and TAg, 
subsequently.

After completion of every treatment, plant material was embedded for microscopic investigations.

\section{Electron microscopy}

Plant particles, treated as indicated, were directly dehydrated in an ethanol series and embedded. Sectioning was started with 1 um thick sections which were investigated with a light-microscope. When plant material appeared in the plastic sections, sectioning was continued with ultra thin $(50-70 \mathrm{~nm})$ sections. These sections were directly observed in a Phillips EM 301 microscope at a magnification of at least $10000 \times$, necessary to visualize Ag grains.

\section{Results}

The meals under investigation originated from seeds which have undergone a number of technological treatments (e.g. milling, heating, extraction). Lightmicroscopic observations revealed that the fine milled plant particles $(<0.2 \mathrm{~mm})$ were very irregular in shape and had severe structural damages. On the surface, the plant particles showed badly destructed cells and cell walls while in the inner part cells remained intact. However, it was possible to recognise and select cells of specific tissue by their colour and morphology with light-microscopy. It should be noted here that thin sections were investigated of plant material which was subjected to physical and chemical processes which could have affected the ordered structure of middle lamellae, primary and secondary cell walls and of cell contents.

\section{Controle incubations of the ETAg procedure}

Enzyme treatment creates reducing end-groups in the cell wall and cell contents if polysaccharides are hydrolysed. The end-groups are detected with silver by means of the TAg part of the staining method.

The presence of in situ occurring reducing end-groups in cell walls was investigated. Figure 1 shows a cell wall fragment from sunflower seed hulls, treated with TAg. Small Ag grains were found (Figure 1, arrow) in a thin layer of approximately $70-80 \mathrm{~nm}$ thickness at the middle lamella. In the other part of the wall (several um's thick) Ag grains were absent. The use of dimedon to block these reactive groups in sunflower seed hulls did not change the occurrence of $\mathrm{Ag}$ grains (not shown). A very limited number of $\mathrm{Ag}$ grains was found (Figure 2, arrow) in palm kernel endocarp, treated with dimedon and TAg. If dimedon was omited, a similar result was obtained (not shown). These results indicate that the total amount of in situ occurring reducing end-groups, in thick-walled tissues of the meals, was very low. When dimedon, denaturated enzyme and TAg were used on palm kernel endocarp, a negligible number of $\mathrm{Ag}$ grains was present (Figure 3). A complete ETAg treatment of palm kernel endocarp with dimedon, enzyme 


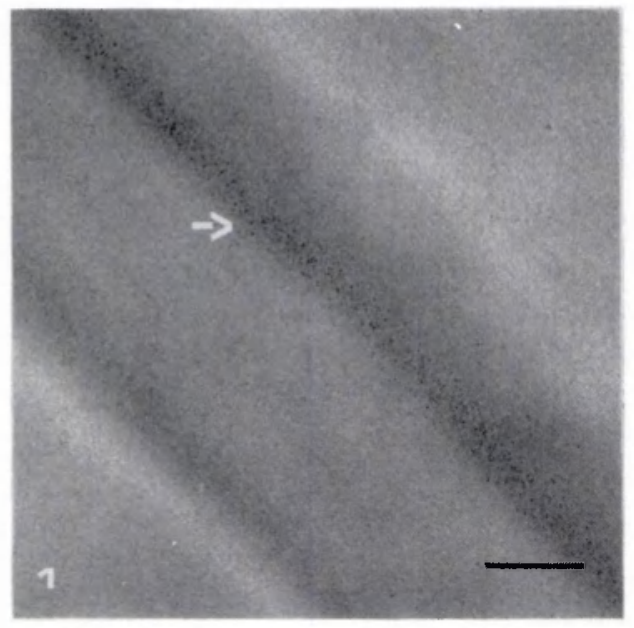

Fig. 1. Cell wall fragment of sunflowed seed hull, treatment: TAg. Fine Ag grains are present around the middle-lamella of the cell wall (arrow). $B a r=200 \mathrm{~nm}$.

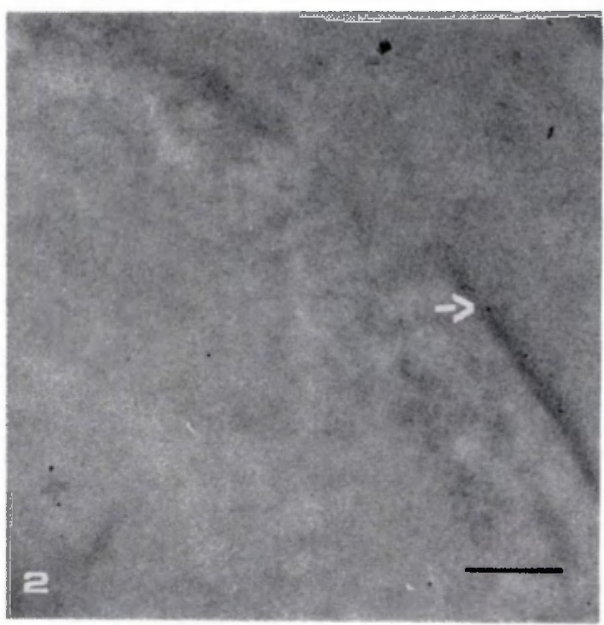

Fig. 2. Cell wall fragment of palm kernel endocarp, treatment: dimedon-TAg. Some silver grains can be found (arrow). Bar $=200 \mathrm{~nm}$.

and TAg, respectively, resulted in silver grains abundantly distributed over the whole cell wall (Figure 4), showing reducing end-groups are formed by the hydrolytic activity of the enzyme.

\section{Sunflower meal treated with enzyme A (ETAg): Seed hull}

The cell walls of cells at the outer margin of the plant particle were hydrolysed during enzyme treatment. At low magnification, it was observed frequently that the cell walls of 1 to 2 cell layers from the surface of the particles were found intensely covered with $\mathrm{Ag}$ grains (Figure 5, top). This proved to be very consistent, indicating that even in tiny plant particles $(0.2 \mathrm{~mm})$, a restricted number of cell walls was hydrolysed. Immediately opposite these dark stained cell walls unstained walls of adjacent cell were found (Figure 5 and $6,=>$ ). The cell walls of these cells were hydrolysed by the enzymes around the cell lumen (Figure 5 , $0->$ ) and around the pitt channels (Figure 6, $0->$ ) indicating that fluids had access to the cell lumina of damaged cells and did not diffuse through the cell walls. Irregular area's with low contrast (Figure 5 and $6-D$ ) were found inside dark stained cell walls. At high magnification, the primary cell wall showed an irregular (Figure 7, IR) and the secondary cell wall a regular (Figure 7, R) pattern of $\mathrm{Ag}$ grains as the result of different orientation of cellulose microfibrils in primary and secondary walls.

\section{Palm kernel meal treated with Driselase (ETAg): Thick walled endosperm}

Driselase activity was found in the thick-walled cells of the endosperm tissue. 


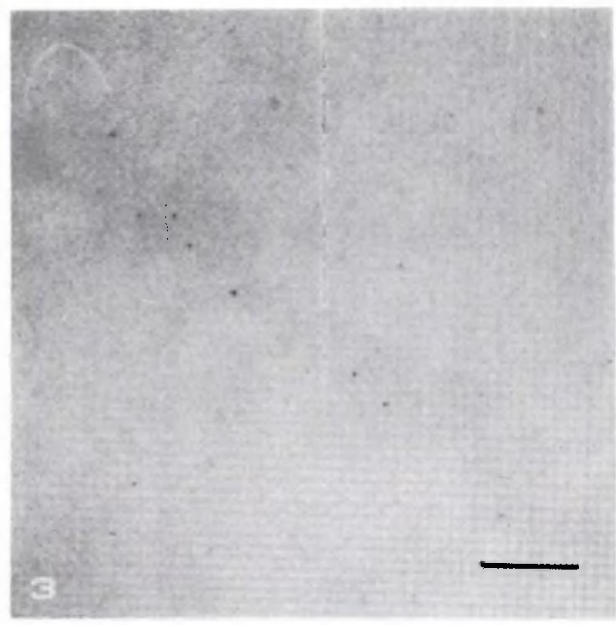

Fig. 3. Cell wall fragment of palm kernel endocarp, treatment: dimedon-denaturated enzymeTAg. Some Ag grains are found after this treatment. Bar $=200 \mathrm{~nm}$.

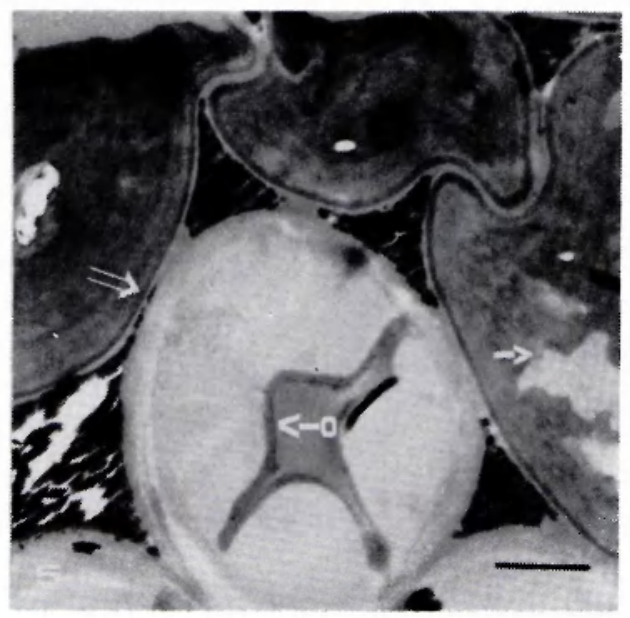

Fig. 5. Sunflower seed hull: ETAg, enzyme A. Low magnification of a plant particle with heavy stained cell walls of cells located at the plant particle surface (on top). The $(=>$ ) points at the middle lamella of a non-hydrolysed wall (right side). A thin layer of the cell wall around the cell lumen (O->) has been hydrolysed. Irregular area's with absence of $\mathrm{Ag}$ grains in the wall are present $(->)$. Bar $=2 \mathrm{um}$.

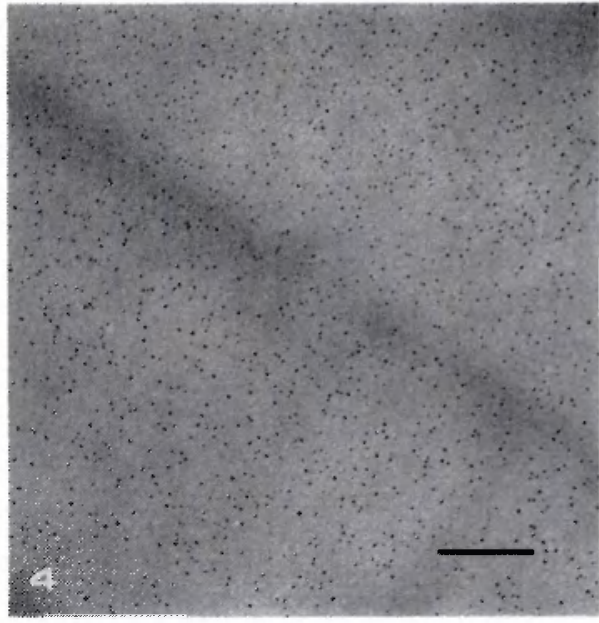

Fig. 4. Cell wall fragment of palm kernel endocarp, treatment: dimedon-ETAg. The enzyme treatment created reducing end-groups visualized with Ag grain deposition. Bar $=200 \mathrm{~nm}$.

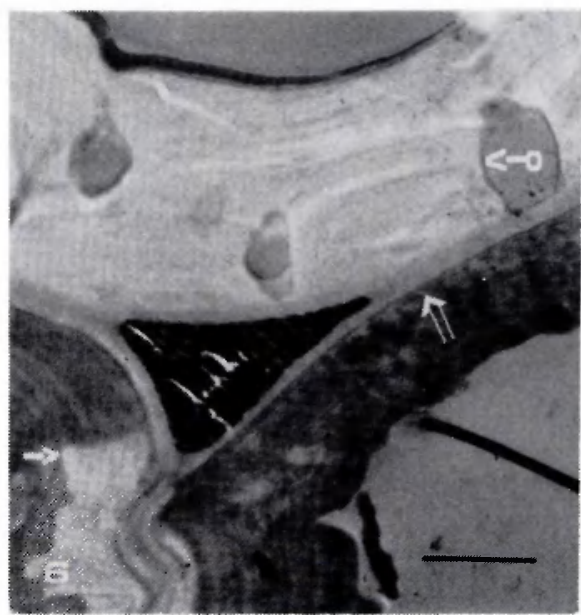

Fig. 6. Sunflowed seed hull: ETAg, enzyme A. Low magnification. The middle lamella-primary wall $(=>$ ) between a negatively (top) and positively (bottom) stained secondary cell wall. The cell wall around the pit channel is hydrolysed $(\mathrm{O}->)$. Negative area's in the walls are present $(->)$. Bar $=2$ um. 


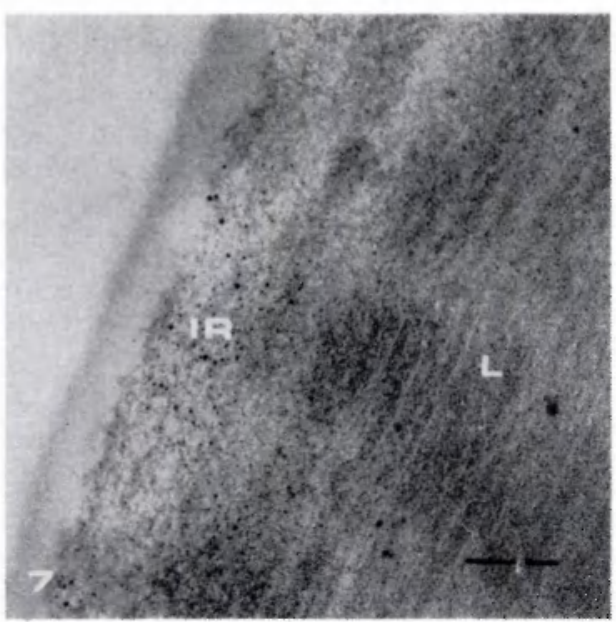

Fig. 7. Sunflower seed hull: ETAg, enzyme A. The arrangement of polysaccharides in the primary wall is irregular (IR) and linear (L) in the secondary wall. Bar $=200 \mathrm{~nm}$.

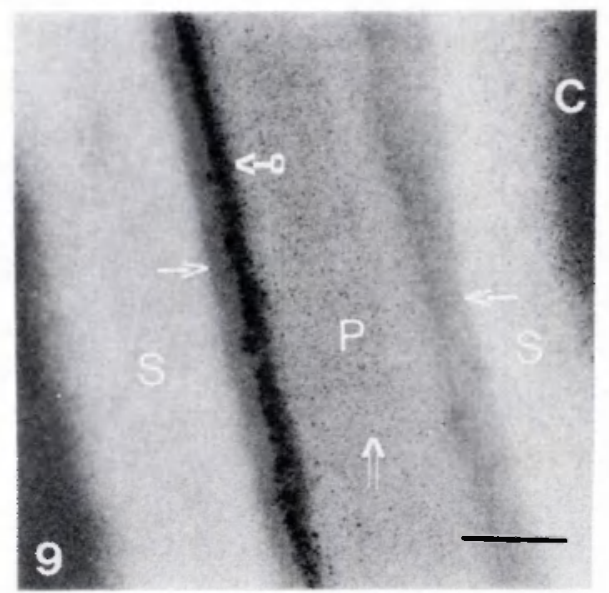

Fig. 9. Parlm kernel endosperm: ETAg, driselase. A fine $\mathrm{Ag}$ deposition $(=>$ ) and an assymetrical $\mathrm{Ag}$ deposition $\left(\mathrm{O}_{-}>\right.$) in the primary wall $(\mathrm{P})$ is present. Electron dense sublayers without $\mathrm{Ag}$ grains present on both sides of the primary wall are obvious $(->)$. In the secondary wall $(S)$ and bordering cell content (C) fine $\mathrm{Ag}$ grains are found. $\mathrm{Bar}=200 \mathrm{~nm}$.

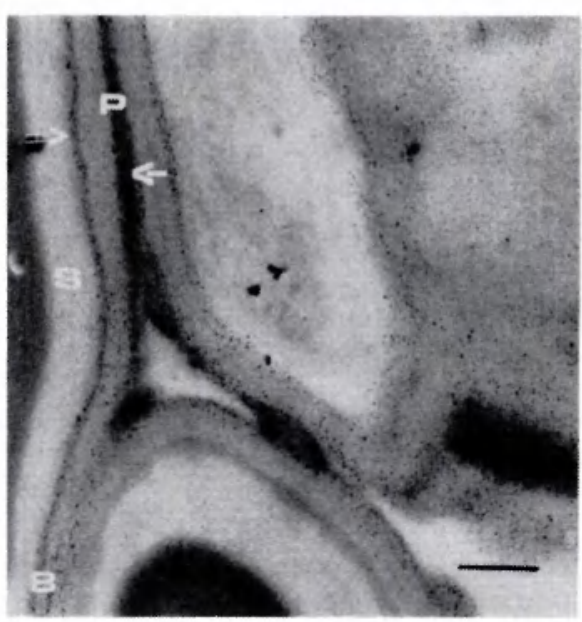

Fig. 8. Palm kernel endosperm: ETAg, driselase. The deposition of Ag grains $(=>)$ in high concentration between the primary wall $(\mathrm{P})$ and secondary wall $(\mathrm{S})$, and in the middle lamellar region $(->)$. Bar $=200 \mathrm{~nm}$.

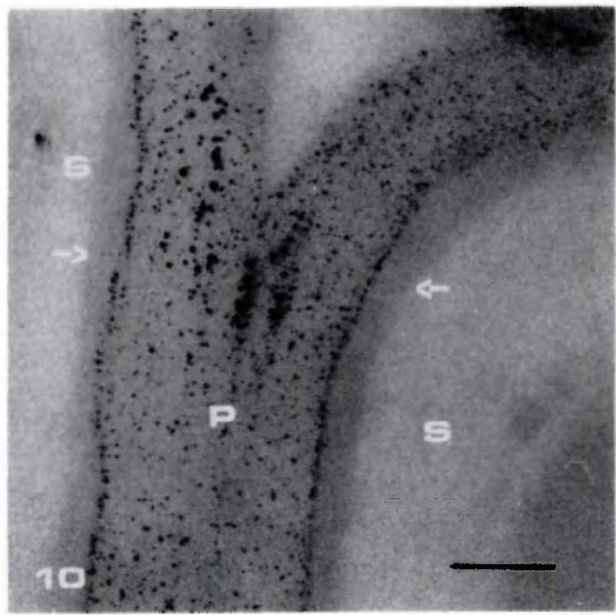

Fig. 10. Palm kernel endosperm: ETAg, driselase. The Ag grains appear in line", paratlel to the cell wall surface. The sublayers between the primary $(P)$ and secondary walls $(S)$ are devoid of $\mathrm{Ag}$ grains $(->)$. Bar $=200 \mathrm{~nm}$. 


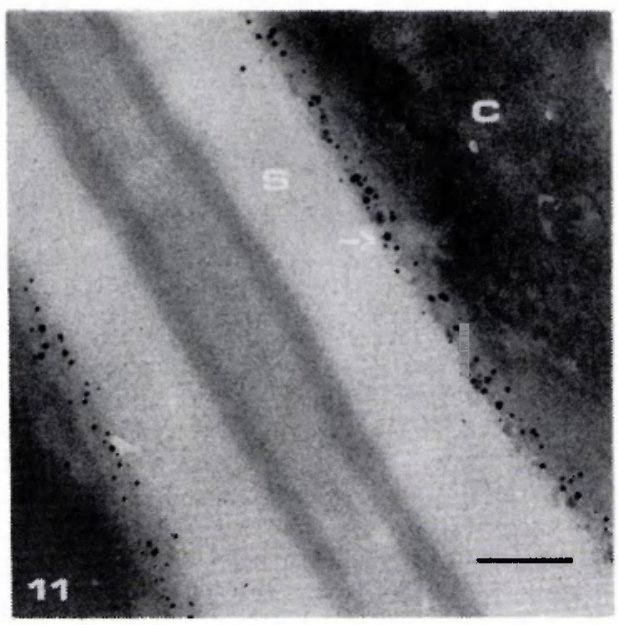

Fig. 11. Palm kernel endosperm: ETAg. gamanase: Deposition of $\mathrm{Ag}$ on the margins of the secondary walls and cell content $(->)$ and inside the cell contents $(C)$. Bar $=200 \mathrm{~nm}$.

Silver staining was found at the margin of the primary $(\mathrm{P})$ and the secondary $(\mathrm{S})$ cell walls and at the middle lamella of the primary wall (Figure 8 , arrows). Small $\mathrm{Ag}$ grains were found in the middle area of the primary wall (Figure 9, $=>$ ). Only in one specific part of the primary wall (P) a deposition of larger Ag grains (Figure $9,0->)$ occurred. The primary or the secondary cell wall contained an electron dense sublayer (Figure 9 and 10, - >) without Ag grains. In all enzyme preparations used, this sublayer was devoid of $\mathrm{Ag}$ grains. Ag grains were found at the surface of and to a limited extend inside the secondary wall and inside the cell content (Figure 9, C). In endosperm tissue, the cell content was often found intensely covered with $\mathrm{Ag}$. Some ordening of the primary wall (P) was observed with Ag grains appearing 'in line' (Figure 10). The size of the silver grains was between 3 and $7 \mathrm{~nm}$, with some large conglomerates of approximately $10 \mathrm{~nm}$.

\section{Palm kernel meal treated with gamanase (ETAg): Thick walled endosperm}

After treatment with gamanase, containing primarily mannanase activity, the primary wall showed sometimes $\mathrm{Ag}$ grains. In the sublayers of primary or secondary walls, Ag grathwere always absent (Figure 11):-At the border of the secondary cell wall $(S)$ and the cell content (C), and at some distance inside the secondary wall, Ag grains were present. Some Ag grains were present in the cytoplasm (Figure 11, C). A strong Ag deposition in the cytoplasm of the endosperm cells was frequently found.

\section{Discussion}

The ETAg technique as described by Joseleau \& Ruel (1985) was applied on thin sections of embedded plant material. However, the embedding substance (epoxyresin) can behave as a chemical barrier during the treatments (Bendayan et al., 
1987). Therefore it was decided to choose for the en-block treatment (embedding afterwards). In addition, the effect of enzymic treatments en-block are more comparable to the situation in the animal's digestive system.

The application of TAg and dimedon-TAg indicated, that in sunflower meal in situ reducing end-groups were present in a very thin wall layer, while in palm kernel meal these groups were nearly absent. In respect to the large number of $\mathrm{Ag}$ grains in both meals when ETAg was used (Figure 4) compared to the low amount of in situ reducing groups, it was decided to omit dimedon in ETAg investigations.

The en-block method showed a distribution of $\mathrm{Ag}$ grains on the cell walls comparable to the results obtained with the original technique (Joseleau \& Ruel, 1985). We found cell walls with $\mathrm{Ag}$ grains 'in line' parallel to the cell wall surface, indicative for differences in hydrolyses of the sub-layers of the cell wall. The distribution of $\mathrm{Ag}$ grains over the cell walls was not always homogeneous, suggesting different concentrations of polysaccharides or different enzyme activities. The size of $\mathrm{Ag}$ grains, 3 to $7 \mathrm{~nm}$, and large grains of $10 \mathrm{~nm}$ agrees with other observations (Joseleau \& Ruel, 1985; Kuga \& Brown, 1988). The large grains of $10 \mathrm{~nm}$ are thought to be the result of coagulation. Silver grains were found in lignified walls of the endocarp of palmpit. This supports earlier observations of Ruel \& Joseleau (1984) that at the surface of lignified sound spruce wood tracheids a limited hydrolysis with enzymes is possible.

The en-block method can be very helpfull to obtain general information on the localization of the effects of enzyme treatments of plant particles. Silver grains were found in cell walls and cell contents of cells located only at the outer surface of the plant particles (Figure 5 and 6, 1-2 cells in depth). In the cell wall irregular area's, without $\mathrm{Ag}$ grains, were observed (Figure 5 and 6). These observations supports Chesson's finding (1988) that glycolytic enzymes are too large to diffuse freely through pores present in the carbohydrate structures of cell walls and that there action is limited in depth. It was observed that $\mathrm{Ag}$ grains were present at some distance from the inner surface of the cell wall (Figure 9 and 11). This must be the effect of hydrolytic activity which partly solubilised the inner surface of the rigid cell wall structure. Graham \& Aman (1991) suggested that enzymes can disrupt cell walls, releasing highly digestible cell contents important for animal arduction. However, in the material investigated herancomplete disruption of Is by enzymic treatment was not found. Furt enereatent ort at particles during $72 \mathrm{~h}$ is insufficient to create largeturtural effects on cell walls. The inner part of the plant particle was unaffected. In our case plant particles $\leq 0.2 \mathrm{~mm}$ were treated. The maximal benefit of enzyme treatment would be expected (in our case) with particles consisting of $2-4$ cells. However, in the animal's digestive system, cell wall digestion, particle size reduction and rate of passage are correlated and thus particle size reduction up to this level would not be applicable. A combined treatment of e.g. steam explosion and enzyme treatment (Toussaint et al., 1991) would be more effective and could create a balance between particle size and breakdown level.

When cell wall hydrolyses results are compared (Figures 8,9 and 10) it could 
be concluded that dricelase has different effects on the same type of cell walls of the endosperm. However, the endosperm is a very large tissue which develops gradually during seed growth and ripening. This could have an effect on cell wall structure and composition.

The ETAg technique is used without a poststaining with heavy metals to avoid contamination with Ag. In the electron micrographs differences in electron density in cell walls and cell contents were found. This naturally occuring contrast has been observed in many other investigations and is ascribed to different concentrations of atomes and molecules in the ultrastructure of cell wall and cell content. In our case this effect could be enhanced by physical and chemical pretreatments of the meals.

The presence of Ag grains in the cell content of the endosperm of palm kernel meal (Figure 10) indicated the presence of polysaccharides in the cytoplasm supporting earlier microscopic observations (Düsterhöft et al., 1991). The presence of polysaccharides in the cell content can be asscribed to the process of cell wall synthesis which was not completed at the time of seed harvest, or to redistribution of cell wall polysaccharides during industrial processing.

The use of enzyme cocktails (dricelase and enzyme A) can demonstrate that, although numerous enzymes are present, total plant particle degradation will be very limited due to certain unaffected sublayers (e.g. Figure 9 and 10). In such cases structural investigations with other enzyme cocktails would help to succesfully overcome breakdown limitations. When a purified enzyme is used (gamanase) specific information on the localization of a substrate in the cell wall and cell contents could be obtained. With the ETAg technique minor amounts of activity can be demonstrated, compared to chemical analyses but it provides only qualitative evidence of hydrolase activity in cell walls and cell contents.

\section{Acknowledgements}

This research was financially supported by Hendrix Nutrition Nederland BV.

\section{References}

Bendayan, M., A. Nanci \& F. W. K. Kan, 1987. Effect of tissue processing on colloidal gold cytochemistry. The Journal of Hisotochemistry and Cytochemistry 35: 983-996.

Chesson, A., 1988. Lignin-polysaccharide complexes of plant cell wall and their effect on microbial degradation in the rumen. Animal Feed Science and Technology 21: 219-228.

Düsterhöft, E. M., A. G. J. Voragen \& F. M. Engels, 1991. Non-starch polysaccharides from sunflower (Helianthus annuus) meal and palm kernel (Elaeis guineensis) meal - Preparation of cell wall material and extraction of polysaccharide fractions. Journal of the Science of Food and Agriculture 55: 411-422.

Graham, H. \& P. Aman, 1991. Nutritional aspects of dietary fibres. Animal Feed Science and Technology 32: 143-158.

Graham, H., K. Hesselmann, E. Jonsson \& A. Aman, 1986. Influence of B- glucanase supplementation on the digestion of a barley based diet in the pig gastrointestinal tract. Nutrional Reports International 34: 1089-1096.

Joseleau, J.-P. \& K. Ruel, 1985. A new cytochemical method for ultrastructural localization of polysaccharides. Biology of the Cell 53: 61-66. 
Kuga, S. \& R. M. Brown Jr., 1988. Silver labeling of reducing ends of bacterial cellulose. Carbohydrate Research 180: 345-350.

Malek, M. A., N. A. Chowdhury, Q. M. Youssouf \& N. Chowdhury, 1988. Bacterial cellulase and saccharification of lignocellulosic materials. Enzyme and Microbial Technology 10: 750-753.

Ruel, K. \& J.-P. Joseleau, 1984. Use of enzyme-gold complexes for the ultrastructural localization of hemicelluloses in plant cell wall. Histochemistry 81: 573-580.

Toussaint, B., G. Excoffier \& M. R. Vignon, 1991. Effect of steam explosion treatment on the physico-chemical characteristics and enzymic hydrolysis of poplar cell wall components. Animal Feed Science and Technology 32: 235-242. 